\title{
A Theoretical Survey of Solvation Effects on Tautomerism Stability of Maleic Hydrazide
}

\author{
ZABIALAH HEIDARNEZHAD ${ }^{1 *}$, FATEMEH HEIDARNEZHAD ${ }^{1}$, \\ FATEMEH HEYDARI ${ }^{2}$, IZATULLO GANIEV ${ }^{3}$ and ZIYODULLO OBIDOV ${ }^{3}$
}

\author{
'Department of Chemistry, Islamic Azad University, Andimeshk, Iran \\ ${ }^{2}$ Department of Physics, Kermanshah Science and Research, Islamic Azad University, \\ Kermanshah, Iran. \\ ${ }^{3}$ Chemistry Institute, Tajikistan Academy of Sciences, Dushanbe, Tajikistan. \\ ${ }^{*}$ Corresponding author E-mail: Z.heidarnezhad @ gmail.com
}

http://dx.doi.org/10.13005/ojc/290438

(Received: November 03, 2013; Accepted: December 14, 2013)

\begin{abstract}
Computational calculations at mp2/cc-pvdz level were employed in the study of tautomers of maleic hydrazide $(\mathrm{MH})$ in the gas phase and selected solvents such as benzene, tetrahydrofuran ethanol, methanol, dimethyl sulfoxide and water using PCM model. All tautomers are optimized at this level. The results show that the tautomer $\mathrm{MH} 2$ is more stable than the other tautomers. In addition, stability of the tautomers in different solvents shows interesting results. Variation of dipole moments and NBO charges on atoms in the solvents were studied.
\end{abstract}

Key words: Maleic hydrazide, Tautomer, PCM model, NBO Charge

\section{INTRODUCTION}

Maleic hydrazide can be easily synthesized by condensation of maleic acid (or anhydride) with hydrazine. Maleic hydrazide $(\mathrm{MH})$ is industrially produced in large quantities and widely used as a plant growth regulator ${ }^{1-10}$. It has been suggested, that the molecules of $\mathrm{MH}$ can act either as a purine analog forming base pairs with uracil and thymine (nucleoside formation through $\mathrm{O}$ atom), or as a pyrimidine analog forming base pairs with adenine (nucleoside formation through $\mathrm{N}$ ) ${ }^{11,12}$.The crystals of $\mathrm{MH}$ were found to exist as three different poly-morphs ${ }^{13-18}$ and, in all the polymorphs, $\mathrm{MH}$ adopts exclusively the oxo-hydroxy form (Scheme 1). Tautomerism of solid maleic hydrazide was studied experimentally using infrared ${ }^{19,20}$ and Raman spectroscopies. The structure and tautomerism of maleic hydrazide were also the subject of several computational studies ${ }^{21-27}$. For the monomeric compound, all the theoretical assessments of relative energies of tautomers agree with the experiment and favor the oxo-hydroxy form.

The common studies of tautomerisation of carbonylic compounds such as hydantoin, uracil, 
thiouracil, 1, 2, 4-triazepines, oxazolidine and hydantoins, can anticipate that maleic hydrazide may exhibit five different tautomeric structures with different conformations. These tautomers have been covered extensively in the literature. However, this study employs density functional theory (DFT) on the investigation of those structures and to present a complete analysis of their relative stabilities in the gas phase and deferent solution. This work includes variation of dipole moments and NBO charges on atoms in the solvents and gas phase. Thereupon, compounds containing different tautomers can be the subject of interest by theoretical chemists ${ }^{33,34}$.

\section{Computational methods}

All these calculations were carried out on a corei7 personal computer by means of GAUSSIAN09 program package. First, all the compound's structures were drawn using Gauss View 03 and optimized in GAUSSIAN09. The tautomers were also optimized in solvents according to the polarisable continuum method of Tomasi and co-workers, which exploits the generating polyhedra procedure ${ }^{28-32}$ to build the cavity in the polarisable continuum medium, where the solute is accommodated. Atomic charges in all the structures were obtained using the Natural
Population Analysis (NPA) method within the Natural Bond Orbital (NBO) approach. ${ }^{33}$

\section{RESULTS AND DISCUSSION}

\section{Gas phase}

Structures and numbering of maleic hydrazide are depicted in Figure 1 and the results of energy comparisons of five tautomers in the gas phase and different solvents are given in Table 1. In the gas phase $\mathrm{MH} 2$ forms are more stable than the other forms. Based on table 2, the most and the least differences between $\mathrm{MH} 2$ and the other forms in gas phase are found for $\mathrm{MH} 1$ with 39.1764 $\mathrm{kcal} \mathrm{mol}^{-1}$ and MH5 $2.170 \mathrm{kcal} \mathrm{mol}^{-1}$ respectively. The order of stability of all the tautomers in the gas phase is $\mathrm{MH} 2>\mathrm{MH} 5>\mathrm{MH} 4>\mathrm{MH} 3>\mathrm{MH} 1$. The calculated dipole moments for the maleic hydrazide are presented in Table 3. MH4 tautomer has the smallest dipole moments than the other five forms with $0.3735 \mathrm{D}$. $\mathrm{MH} 3$ tautomer with $\mathrm{N}=\mathrm{N}$ bond has the largest dipole moments with 5.9022D in water. The major diûerence of dipole moment is belonged to $\mathrm{MH} 3$ form with 2.14D in gas and water phase. The calculated values NBO charges using the natural population analysis (NPA) of optimized structures of

Table 1: Total energies ${ }^{a}$ at MP2/CC-PVDZ in the gas phase and solvents

\begin{tabular}{lcccccc}
\hline Tautomer & Gas(1.0) & Benzene(2.2) & THF(7.6) & Eethanol(32.6) & DMSO(46.7) & Water(78.4) \\
\hline NH1 & -413.5731879 & -413.578105 & -413.5810667 & -413.5820284 & -413.5822236 & -413.5824851 \\
MH2 & -413.6356196 & -413.640947 & -413.6441534 & -413.6451944 & -413.6450538 & -413.6455019 \\
MH3 & -413.5847853 & -413.590442 & -413.5939216 & -413.5950622 & -413.5952943 & -413.5954004 \\
MH4 & -413.6214027 & -413.627871 & -413.6318362 & -413.6331333 & -413.6333971 & -413.6335176 \\
MH5 & -413.6321614 & -413.636837 & -413.6395906 & -413.6405654 & -413.6406536 & -413.6407353 \\
\hline
\end{tabular}

aHartree.

Table 2: Energy ${ }^{\mathrm{a}}$ difirrence between the tautomers of maleic hydrazide

\begin{tabular}{lcccccc}
\hline Tautomer & Gas(1.0) & Benzene(2.2) & THF(7.6) & Eethanol(32.6) & DMSO(46.7) & Water(78.4) \\
\hline NH1 & -0.0624317 & -0.0628421 & -0.0630867 & -0.0631660 & -0.0628302 & -0.0630168 \\
MH2 & 0.0000000 & 0.0000000 & 0.0000000 & 0.0000000 & 0.0000000 & 0.0000000 \\
MH3 & -0.0508343 & -0.0505048 & -0.0502318 & -0.0501322 & -0.0497595 & -0.0501015 \\
MH4 & -0.0142169 & -0.0130762 & -0.0123172 & -0.0120611 & -0.0116567 & -0.0119843 \\
MH5 & -0.0034582 & -0.0041104 & -0.0045628 & -0.0046290 & -0.0044002 & -0.0047666 \\
\hline
\end{tabular}

aHartree. 
Table 3: Calculated dipole moments of optimized tautomers of maleic hydrazide (Deby)

\begin{tabular}{lcccccc}
\hline Tautomer & Gas(1.0) & Benzene(2.2) & THF(7.6) & Eethanol(32.6) & DMSO(46.7) & Water(78.4) \\
\hline NH1 & 3.3174 & 3.7843 & 4.105 & 4.2163 & 4.2393 & 4.3869 \\
MH2 & 3.3595 & 3.8164 & 4.1266 & 4.2335 & 4.2555 & 4.2657 \\
MH3 & 4.8824 & 5.4123 & 5.7538 & 5.868 & 5.8915 & 5.9022 \\
MH4 & 0.3733 & 0.4389 & 0.4853 & 0.5015 & 0.5049 & 0.5065 \\
MH5 & 1.7491 & 2.1098 & 2.3626 & 2.4604 & 2.4695 & 2.4779 \\
\hline
\end{tabular}

Table 4. Calculated NBO charges on ring atoms of maleic hydrazide

\begin{tabular}{|c|c|c|c|c|c|c|c|}
\hline Atom & Tautomer & Gas & Benzene & THF & Ethanol & DMSO & Water \\
\hline N1 & $\mathrm{MH} 1$ & -0.2690 & -0.2431 & -0.2576 & -0.2627 & -0.2637 & -0.2642 \\
\hline N2 & & -0.1926 & -0.2061 & -0.1991 & -0.1967 & -0.1962 & -0.1960 \\
\hline $\mathrm{C} 3$ & & -0.5150 & 0.5252 & 0.5196 & 0.5175 & 0.5171 & 0.5169 \\
\hline $\mathrm{C} 4$ & & -0.2505 & -0.2726 & -0.2628 & -0.2593 & -0.2585 & -0.2582 \\
\hline C5 & & -0.5418 & -0.5358 & -0.5375 & -0.5381 & -0.5383 & -0.5383 \\
\hline $\mathrm{C} 6$ & & 0.8577 & 0.8451 & 0.8551 & 0.8584 & 0.8591 & 0.8594 \\
\hline N1 & $\mathrm{MH} 2$ & -0.5080 & -0.5014 & -0.4999 & -0.4994 & -0.4992 & -0.4992 \\
\hline $\mathrm{N} 2$ & & -0.3800 & -0.3821 & -0.3851 & -0.3861 & -0.3862 & -0.3863 \\
\hline $\mathrm{C} 3$ & & 0.6513 & 0.6509 & 0.6542 & 0.6553 & 0.6555 & 0.6557 \\
\hline $\mathrm{C} 4$ & & -0.2452 & -0.2400 & -0.2343 & -0.2322 & -0.2318 & -0.2316 \\
\hline C5 & & -0.2465 & -0.2506 & -0.2544 & -0.2557 & -0.2560 & -0.2562 \\
\hline $\mathrm{C} 6$ & & 0.8056 & 0.8084 & 0.8116 & 0.8126 & 0.8127 & 0.8128 \\
\hline $\mathrm{N} 1$ & MH3 & -0.2008 & -0.2054 & -0.208 & -0.209 & -0.2092 & -0.209 \\
\hline N2 & & -0.2108 & -0.2183 & -0.223 & -0.2247 & -0.225 & -0.225 \\
\hline C3 & & 0.8092 & 0.8265 & 0.8368 & 0.8401 & 0.8408 & 0.8411 \\
\hline $\mathrm{C} 4$ & & -0.5162 & -0.5167 & -0.517 & -0.517 & -0.517 & -0.517 \\
\hline C5 & & -0.506 & -0.506 & -0.506 & -0.5059 & -0.5059 & -0.506 \\
\hline C6 & & 0.815 & 0.83 & 0.8388 & 0.8417 & 0.8422 & 0.8425 \\
\hline N1 & $\mathrm{MH} 4$ & -0.3667 & -0.3813 & -0.391 & -0.3945 & -0.3952 & -0.396 \\
\hline N2 & & -0.3667 & -0.3813 & -0.391 & -0.3946 & -0.3952 & -0.396 \\
\hline C3 & & 0.6282 & 0.6321 & 0.6346 & 0.6354 & 0.6356 & 0.6357 \\
\hline C4 & & -0.249 & -0.2456 & -0.243 & -0.2421 & -0.242 & -0.242 \\
\hline C5 & & -0.249 & -0.2456 & -0.243 & -0.2421 & -0.2419 & -0.242 \\
\hline $\mathrm{C} 6$ & & 0.6282 & 0.6321 & 0.6346 & 0.6354 & 0.6356 & 0.6357 \\
\hline $\mathrm{N} 1$ & MH5 & -0.5529 & -0.5505 & -0.549 & -0.5478 & -0.5476 & -0.548 \\
\hline $\mathrm{N} 2$ & & -0.5528 & -0.5505 & -0.549 & -0.5478 & -0.5476 & -0.548 \\
\hline $\mathrm{C} 3$ & & 0.834 & 0.8434 & 0.8486 & 0.8503 & 0.8506 & 0.8507 \\
\hline $\mathrm{C} 4$ & & -0.2522 & -0.2504 & -0.249 & -0.2488 & -0.2487 & -0.249 \\
\hline C5 & & -0.2519 & -0.2501 & -0.249 & -0.2485 & -0.2484 & -0.248 \\
\hline C6 & & 0.834 & 0.8433 & 0.8486 & 0.8502 & 0.8505 & 0.8507 \\
\hline
\end{tabular}




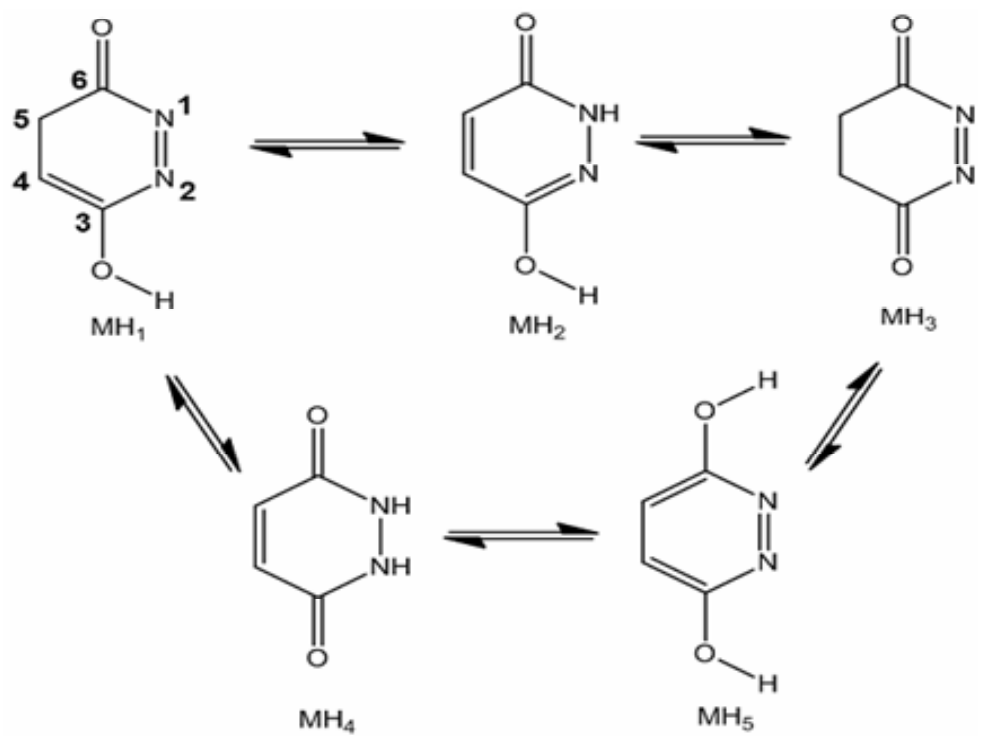

Fig. 1: Tautomeric forms of maleic hydrazide

maleic hydrazides tautomers in the gas phase and solvents are listed in Table 4. In MH5 form, N1 atom carries the largest negative charge, in $\mathrm{MH} 2, \mathrm{MH} 4$ and $\mathrm{MH} 5$ nitrogen atoms at position 1 or 2 carry the largest negative charge, in $\mathrm{MH} 3$ and $\mathrm{MH} 1$ carbon atoms at position 4 or 5 carry the largest negative charge and these positions will most effectively interact with electrophiles.

\section{Solvent effects}

Solvent effects are relevant in tautomers stability phenomena, since polarity differences among tautomers can induce significant changes in their relative energies in solution. $\mathrm{PCM} / \mathrm{mp} 2$ calculations were used to analyze the solvent effects on tautomerism of maleic hydrazides. It is important to stress that the PCM model does not consider the presence of explicit solvent molecules; hence specific solute-solvent interactions are not described and the calculated solutions effects arise only from mutual solute-solvent electrostatic polarization. The data presented in Table 1 show that polar solvents increase the stability of all maleic hydrazide tautomers in compare to gas phase. The difference between the total energies of maleic hydrazide and the other forms shows a regular trend when changing from gas phase to more polar solvents (water). In solvent phase the order of stability of all the tautomers is $\mathrm{MH} 2>\mathrm{MH} 5>\mathrm{MH} 4>\mathrm{MH} 1>\mathrm{MH} 3$. The dipole moments increases by changing the gas phase to the solution as well as by increasing the solvent polarity. The most significant variations being obtained in $\mathrm{MH} 3$ form with $5.09022 \mathrm{D}$. We have examined the charge distribution of tautomers in the solvent as well as gas phase by using calculated NBO charges. The charge distribution in solvents with increase of polarity differently varies for any atoms.

\section{CONCLUSION}

1. In the gas phase $\mathrm{MH} 2$ form was more stable than the other tautomers. Total energy of all forms are effected by solvent. With increase of polarity total energy of all compounds were more negative.

2. The dipole moments of all compounds are affected by solvent. With increase of the polarity of solvents the dipole moments of all tautomers were increased.

3. The charges on all six positions were affected by solvents. In addition with increase of dielectric constant a variation was found. 


\section{REFERENCES}

1. R.H. Moore., Science. 112: 52-53 (1950).

2. B.E. Struckmeyer.,Am. J. Bot. 40: 25-29 1953.

3. D. Coupland, A. J. Peel., Planta. 105: 66-70 1972.

4. B.E. Struckmeyer., G.G, Weis.,J.A. Schoenemann.,Am. Potato J. 58: 611-618 (1981).

5. A.I. Dias., H.J. Duncan., Potato Res. 42: 95-99 (1999).

6. J.C. Nath., K. Baruah., Indian J. Agric. Sci. 69: 292-294 (1999).

7. T. Gichner., M. Menke., D.A. Stavreva., I. Schubert., Mutagenesis. 15: 385-389 (2000).

8. G. Ferrara., E. Loffredo., N. Senesi., Euro. J. Soil Sci. 55: 449-458 (2004).

9. K. Grevsen., J.N. Sorensen., J. Horticultural Sci. Biotechnol. 79: 877-884 (2004).

10. L. Marcano., I. Carruyo., A. Del Campo., X. Montiel., Environ. Res. 94: 221-226 (2004).

11. D. Coupland., A.J. Peel., Planta. 103: 249-253 (1972).

12. P.D. Cradwick., Nature .258: 774 (1975).

13. P.D. Cradwick., J. Chem. Soc. - Perkin Trans. 2: 1386-1389 (1976).

14. D. Hall., C.E.L. Headford.,J. Comput. Chem. 1: 261-265 (1980).

15. A. Katrusiak., Acta Crystallogr. Sect C-Cryst. Struct. Commun. C49: 36-39 (1993).

16. A. Katrusiak., Acta Crystallogr. Sect. B Struct. Sci. B57: 697-704 (2001).

17. C.B. Aakeröy, A.M. Beatty, B.A. Helfrich, M. Nieuwenhuyzen, Cryst. Growth Des. 3: 159165 (2003).

18. L. Fábián, A. Kálmán, Acta Crystallogr. Sect. B - Struct. Sci. B60: 547-558 (2004).

19. J.U.N. Cheinker, T.V. Gortinskaia, P. Sycheva, J. Chim. Phys. Physico-Chim. Biol. 55: 217226 (1958).
20. B. Morzyk-Ociepa, J. Mol. Struct. 833: 121 132 (2007).

21. W.M.F. Fabian, J. Mol. Struct. 206: 295-307 (1990).

22. W.M.F. Fabian, J. Comput. Chem. 12: 17-35 (1991).

23. H.J. Hofmann, R. Cimiraglia, J. Tomasi, R. Bonaccorsi, J. Mol. Struct. 227: 321-326 (1991).

24. N.A. Burton, D.V.S. Green, I.H. Hillier, P.J. Taylor, M.A. Vincent, S. Woodcock, J. Chem. Soc. - Perkin Trans. 2: 331-335 (1993).

25. J.R. Greenwood, H.R. Capper, R.D. Allan, G.A.R. Johnston, Internet J. Chem. 1: CP1U63 (1998).

26. Z.Y.Zhou, X.Wu, Z.M. Su, Y.Z. Xie, X.M. Pan, W.B. Ding, Acta Chim. Sin. 62: 2244-2252 (2004).

27. Miertus, S., Scrocco, E., Tomasi, J., J. Chem. Phys., 55: 117 (1981).

28. Cances, M.T., Mennucci, V., Tomasi, J., J. Chem. Phys., 107: 3032 (1997).

29. Cossi, M., Barone, V., Mennucci, B., Tomasi, J., Chem. Phys. Lett., 286: 253 (1998).

30. Barone, V., Cossi, M., Tomasi, J., J. Comp. Chem., 19: 404 (1998).

31. Barone, V., Cossi, M., J. Phys. Chem. A.,102: 1995 (1998).

32. Reed, A.E., Curtiss, L.A., Wienhold, F., Chem. Rev., 88: 899 (1988).

33. Zabialah, H., F,Heidarnezhad., I,Ganiev., Z,Obidov.,M,S.Sharifi., Orient J. Chem., 28(4), 1597-1604 (2012).

34. Zabialah, H., F,Heidarnezhad., I,Ganiev., Z,Obidov.,M,S.Sharifi., Orient J. Chem., 29(1): 53-58 (2013).

35. Zabialah, H., F,Heidarnezhad., F,Heydari., E,Bahramian.,M,S. Orient J. Chem., 29(1): 69-74 (2013). 